\title{
O ENSINO JURÍDICO E A CONSTRUÇÃO DO ESTADO BRASILEIRO PÓS-INDEPENDÊNCIA: Das Academias ao Poder
}

\author{
http://dx.doi.org/10.21527/2176-6622.2019.51.78-87
}

Recebido em: 30/1/2019

Modificações requeridas em: 26/5/2019

Aceito em: 5/6/2019

\section{Fernando Fortes Said Filho}

Doutorando em Direito Constitucional pela Unifor. Mestre em Direito Público pela Unisinos. Professor do Instituto Federal do Piauí (IFPI). Advogado. ffsaidfilho@hotmail.com

\section{RESUMO}

Os primeiros cursos jurídicos no Brasil foram criados em 1827, com a instalação das faculdades de Direito de São Paulo e Olinda (esta última transferida para Recife em 1854). Essas Academias desempenharam relevante papel no projeto de desenvolvimento do país no período pós-independência, pois formaram inúmeros bacharéis que até hoje são lembrados por suas notáveis contribuições na história brasileira, apesar de poucos terem se destacado por sua atuação na área jurídica. Mediante uma pesquisa bibliográfica realizada pelo levantamento de referências teóricas na literatura brasileira, além da análise de documentos históricos, o presente artigo tem por objetivo analisar o que se ensinava nas tradicionais faculdades de Direito do Brasil nas primeiras décadas da criação dos cursos superiores. Nesse sentido, chegou-se à conclusão que os cursos de direito, mais do que a produção do conhecimento jurídico, estavam voltados à formação de uma elite ideologicamente integrada de acordo com os interesses do modelo político-liberal que se pretendia estabelecer, servindo as Academias como centro de recrutamento de profissionais para a composição dos quadros da burocracia estatal, incluindo o Poder Judiciário. Em outros termos, era por meio das faculdades de São Paulo e Olinda/Recife que se forjava o bacharel responsável pela formatação da organização política e econômica então desejada pela elite dominante à época.

Palavras-chave: Cursos jurídicos. Pós independência. Bacharel. Burocracia estatal.

\section{LEGAL EDUCATION AND THE CONSTRUCTION OF THE BRAZILIAN STATE AFTER INDEPENDENCE:} FROM ACADEMIES TO POWER

\section{ABSTRACT}

The first legal courses in Brazil were created in 1827, with the installation of the law faculties of São Paulo and Olinda (the latter transferred to Recife in 1854). These Academies played a significant role in the development of the country in the post-independence period, since they formed numerous bachelors that until today are remembered for their remarkable contributions in Brazilian history, although few have stood out for their work in the legal area. Through a bibliographical research carried out by the survey of theoretical references in the Brazilian literature, besides the analysis of historical documents, this article aims to analyze what was taught in the traditional Brazilian law schools in the first decades of the creation of higher education. In this sense, it was concluded that the law courses, rather than the production of legal knowledge, were aimed at the formation of an ideologically integrated elite according to the interests of the political-liberal model that was intended to be established, serving the Academies as a recruitment center of professionals for the composition of the cadres of the state bureaucracy, including the Judiciary. In other words, it was through the faculties of São Paulo and Olinda/Recife that the bachelors responsible for the format of the political and economic organization then desired by the dominant elite at the time were forged.

Keywords: Legal courses Post independence. Bachelor. State bureaucracy.

\section{SUMÁRIO}

1 Introdução. 2 A criação dos cursos jurídicos no Brasil: que tipo de bacharel se formava. 3 A construção do Estado brasileiro pela elite: o papel do ensino jurídico na formação ideológica dos burocratas. 4 Reflexos da burocracia no Poder Judiciário brasileiro. 5 Considerações finais. 6 Referências. 


\section{INTRODUÇÃO}

Num país onde significativa parte da população era pobre e analfabeta, muito em razão da falta de interesse da Corte em equipar a colônia com um sistema educacional eficiente, o Ensino Superior era acessível apenas a determinadas famílias que podiam arcar com os custos da formação dos seus filhos em Coimbra. Esse caráter excludente da educação brasileira foi mantido no período pós-independência, quando, a despeito dos debates na Assembleia Constituinte a partir de 1823 acerca do ensino nacional, as elites políticas optaram pela criação de cursos superiores em detrimento de escolas básicas, estas últimas mais apropriadas à realidade de um Estado ainda em formação.

Foi apenas no ano de 1827 que surgiram os primeiros cursos de direito no Brasil, com a criação das faculdades de São Paulo e Olinda (posteriormente transferida para Recife). Esses dois cursos, no entanto, desde o seu nascedouro, foram alvo de constantes críticas acerca da qualidade do ensino que propunham. De fato, diversas foram as constatações acerca da precariedade das instalações destinadas às academias, a falta de compromisso de considerável parte dos professores e o desempenho dos alunos que, de certa forma, pouco se mostravam interessados no aprendizado jurídico.

Ainda assim, não se pode desprezar que os cursos de direito desempenharam importante papel na história da formação do Estado brasileiro, até porque as academias de São Paulo e Olinda/Recife forneceram inúmeros bacharéis que até hoje são lembrados por suas notáveis contribuições, tais como Rui Barbosa, Joaquim Nabuco, Castro Alves, Ariano Suassuna, Campos Sales, Prudente de Moraes, Afonso Pena, Jânio Quadros, Álvares de Azevedo, Monteiro Lobato, Eusébio de Queiroz, Tobias Barreto, apenas para citar alguns. Curiosamente, poucos se destacaram pela atuação na área jurídica, sobretudo aqueles que teriam estudado nos primeiros anos das faculdades.

Nesse sentido, o presente artigo propõe uma análise acerca daquilo que realmente se ensinava nas tradicionais Faculdades de Direito do Brasil (São e Paulo e Olinda/Recife), no intuito de traçar um possível perfil do bacharel como produto do ensino jurídico nas primeiras décadas da criação dos cursos superiores. Para tanto, tendo por base as contribuições de Adorno, Carvalho, Venâncio Filho, Bastos e outros historiadores, pretendeu-se examinar o contexto político de construção do país no período pós-independência, principalmente em relação aos interesses da elite dominante como fator de interferência na formação ideológica dos bacharéis e o recrutamento de tais profissionais para integrar a burocracia estatal. Ao final, estabelecidas algumas premissas, foram feitas considerações acerca das implicações desse modelo de dominação política na composição e atuação do Poder Judiciário à época.

\section{A CRIAÇÃO DOS CURSOS JURÍDICOS NO BRASIL: Que Tipo de Bacharel se Formava}

A história do Ensino Superior no Brasil se confunde, em parte, com a criação dos cursos de Direito no país em $1827,{ }^{1}$ ainda que tardiamente, se comparada ao período de instalação das primeiras universidades na América espanhola. ${ }^{2}$ Mais especificamente, no dia 11 de agosto foi promulgada a lei que criava os cursos de ciências jurídicas e sociais nas cidades de São Paulo e Olinda (este último viria a ser transferido para Recife em 1854), apesar de os debates em torno da matéria já terem se iniciado na Assembleia Constituinte quatro anos antes.

A primeira manifestação oficial acerca do tema foi de iniciativa do deputado José Feliciano Fernandes Pinheiro - futuro visconde de São Leopoldo - que, no seu projeto de lei apresentado em 14 de junho de 1823 na Assembleia Constituinte, propunha a criação, pelo Império, de uma universidade na cidade de São Paulo,

\footnotetext{
Diz-se em parte porque, já em 1808, com a chegada da família real portuguesa no Brasil e a consequente necessidade de qualificação de profissionais para compor o novo cenário político e econômico nacional, foram instalados alguns cursos específicos, tais como o de cirurgia no Hospital Militar da Bahia e o de formação de oficiais engenheiros civis e militares na Academia Real de Marinha (RIBEIRO, 1998, p. 41).

2 De acordo com Luzuriaga (1990, p. 133-134), as primeiras universidades responsáveis por difundir a cultura hispano-americana foram fundadas ainda no ano de 1551, no Peru (Universidade de São Marcos) e no México. Posteriormente, viriam a ser criadas a Universidade de Santo Tomás na Colômbia, no ano de 1580, o Colégio Máximo de Estudos Superiores, na cidade Argentina de Córdoba, em 1613 e a Real Universidade de São Felipe, em Santiago no Chile, no ano de 1623. Acrescente-se, ainda, a Universidade de São Domingos que, apesar de não ter prosperado, teria sido instalada em 1538.
} 
na qual funcionasse a Faculdade de Direito Civil. A referida proposta, após apresentado o substitutivo da Comissão de Instrução Pública no sentido de que fossem criadas duas universidades (uma em São Paulo e outra em Olinda), apesar de ter sido aprovada, não chegou a ser promulgada, haja vista a dissolução da Assembleia (PAULO FILHO, 1997, p. 129).

Já na Constituição outorgada em 1824 por D. Pedro I, optou-se por fazer constar no item XXXIII do artigo $179^{3}$ a previsão da criação de colégios e universidades onde seriam ensinados os elementos de ciências, belas artes e artes. Este fato teria ensejado, em janeiro de 1825, a edição de um decreto do imperador instituindo provisoriamente um curso jurídico no Rio de Janeiro, cabendo a elaboração dos estatutos a Luiz José de Carvalho e Melo, o visconde de Cachoeira. Os estatutos até foram elaborados, porém o curso não foi instalado (REALE JÚNIOR, 2013-2014, p. 89).

A efervescência dos debates sobre a necessidade de criação dos cursos jurídicos reflete o contexto em que se encontrava o Brasil pós-independência: um país destituído de qualquer forma organizada de escolaridade e que pretendia alcançar sua autonomia cultural e política. A construção do Estado brasileiro perpassava, pois, segundo Xavier (1980, p. 22), pela estruturação da educação nacional, não uma mera substituição ou reforma - uma vez que era praticamente inexistente - mas da elaboração de um sistema, tendo a preocupação com o Ensino Superior prevalecido sobre a educação básica. ${ }^{4} E s s a$ opção demonstra que a elite política brasileira, mais do que preocupada com a universalização da educação no território nacional, estava interessada, mesmo, era no produto a ser gerado pelas faculdades de Direito: o bacharel, profissional que desempenharia relevante função no projeto de construção do país. Era justamente a partir das Academias que a elite dirigente delineava o processo de consolidação do Estado brasileiro, por meio da formação de intelectuais que, posteriormente, seriam recrutados para compor a estrutura político-administrativa do governo.

A implantação dos dois primeiros cursos de Direito no Brasil, em 1827, um em São Paulo e outro em Recife (transferido de Olinda, em 1854), refletiu a exigência de uma elite sucessora da dominação colonizadora, que buscava concretizar a independência político-cultural, recompondo, ideologicamente, a estrutura de poder e preparando nova camada burocrático administrativa, setor que assumiria a responsabilidade de colonizar o país. Nesse sentido, os cursos jurídicos surgiram, concomitantemente, com o processo de independência e de construção do Estado nacional (WOLKMER, 1999, p. 80).

O fato é que a declaração da independência brasileira não representaria a ruptura imediata com a influência dos valores da metrópole. Em verdade, o Brasil herdaria o modelo português de manutenção da unidade da elite intelectual, tradicionalmente composta por bacharéis, o que levou Feitosa (2006, p. 109) a afirmar que "a verdadeira função destes cursos consistia em garantir maior coesão na formação de uma elite nacional, de modo semelhante ao ocorrido em Portugal através da Universidade de Coimbra".

Em outros termos, o bacharelismo ${ }^{5}$ não é uma exclusividade da história brasileira. $O$ reconhecimento das profissões liberais já era evidente há muito em Portugal, pois "em quase todas as épocas da história portuguesa uma carta de bacharel valeu quase tanto como uma carta de recomendação nas pretensões a altos cargos públicos" (HOLANDA, 1995, p. 157). Essa tradição viria a ser absorvida pelas elites políticas nacionais que, ainda em busca da formação de um pensamento autêntico, externavam a natural influência dos mais de três séculos de colonização e contato com as concepções lusitanas.Mesmo, porém, diante da relevância dos cursos de Direito para a constituição de uma doutrina política própria, o ensino jurídico continuava restrito às faculdades de São Paulo e Olinda/Recife, perdurando, assim, até o final do Império. Venâncio Filho (2011,

\footnotetext{
3 Artigo 179. A inviolabilidade dos Direitos Civis, e Politicos dos Cidadãos Brazileiros, que tem por base a liberdade, a segurança individual, e a propriedade, é garantida pela Constituição do Imperio, pela maneira seguinte.

XXXIII. Collegios, e Universidades, aonde serão ensinados os elementos das Sciencias, Bellas Letras, e Artes.

${ }_{4}$ Em determinadas situações era possível observar certa resistência parlamentar ao projeto de criação dos cursos superiores em detrimento da educação de base. Uma ocasião específica foi relatada por Xavier (1980, p. 32), quando citou trecho do discurso do deputado Francisco Gê Acayaba Montezuma na sessão de 27 de agosto de 1823: "Não se pense, porém, que nego a necessidade de ilustração nos brasileiros; antes porque a conheço é que me oponho ao estabelecimento de duas universidades e aprovaria o estabelecimento de alguns colégios; antes dois, quatro ou seis colégios do que duas universidades (...) tem-se falado muito do atraso da educação primária da mocidade, falta de mestres e de outras muitas coisas que tendem a mostrar que ainda não podemos ter duas universidades (...)".

O termo bacharelismo é empregado no presente artigo com base nas lições de Medina (2009, p. 40), para fazer menção ao fenômeno caracterizado pela predominância do bacharel na vida social do país, sobretudo no que concerne à posição de destaque comumente ocupada por ele na atividade política, traço marcante da realidade brasileira no período subsequente à declaração da independência.
} 
p. 113) ressalta que, se quantitativamente o ensino permanecia o mesmo desde 1827 , qualitativamente a situação também não se modificou, apontando o autor que a precariedade das instalações materiais, o quadro docente e até mesmo o desinteresse dos alunos, teriam sido alguns fatores determinantes para o descrédito dos cursos.

O corpo docente das faculdades, tanto de São Paulo quanto de Olinda/Recife, foi alvo de constantes críticas durante os primeiros anos do curso de Direito. Na verdade, numa sociedade onde o número de bacharéis era inexpressivo e debilmente qualificado, poucos se habilitavam à carreira de lente e, mesmo aqueles que iniciavam a atividade magisterial, o faziam de forma insatisfatória por não a considerar atrativa:

O ofício do professor era uma atividade auxiliar no quadro do trabalho profissional. A política, a magistratura, a advocacia, representavam para os professores, na maioria dos casos, a função principal. E aqueles que a ela só se dedicavam por vocação ou por desinteresse de outras atividades sofriam na própria carne a consequência de sua imprevidência (VENÂNCIO FILHO, 2011, p. 121).

A grande maioria dos professores não se dedicava com afinco à carreira docente. Poucos se prestavam a elaborar compêndios e a preparar suas preleções, sendo bastante comum a prática de aulas lidas ou mesmo a inserção de debates políticos em sala de aula. Essa postura apática dos lentes, aliada à extrema benevolência nos exames e à ausência de controle da frequência dos alunos, eram aspectos relevantes na formação de bacharéis que pouco - ou quase nada - absorviam em termos de conhecimento jurídico ao longo do curso (VENÂNCIO FILHO, 2011, p. 116-117).

Ainda assim, a análise do perfil dos discentes nas primeiras décadas do ensino jurídico não pode restar vinculada apenas à carente atuação dos mestres. É preciso relembrar que, quando da instalação dos cursos de Direito, o Brasil não dispunha sequer de uma organização mínima do ensino secundário, capaz de contribuir com a educação da mocidade nacional. Dessa maneira, não era de surpreender o baixo nível de conhecimento dos alunos que ingressavam nas faculdades. Além do mais, não se pode olvidar que nem todos que ali entravam se interessavam pelos ensinamentos jurídicos, pois boa parte dos jovens estava voltada apenas ao prestígio que alcançariam na sociedade pelo título de bacharel. ${ }^{6}$ Sob essa perspectiva, é quase inequívoca a constatação de que as Academias brasileiras não estavam voltadas à formação de jurisconsultos, intelectuais que poderiam se destacar pelo vasto conhecimento técnico-jurídico adquirido durante os anos de interações com os professores em sala de aula. Pelo contrário, "as escolas de Direito foram criadas efetivamente para atender às necessidades burocráticas do Estado Nacional em emergência" (ADORNO, 1988, p. 141), ou seja, os debates no âmbito das faculdades privilegiavam a formação política dos alunos em lugar de um ensino propriamente jurídico.

Assim, consoante as lições de Rodrigues (1988, p. 11)

A criação de nossos primeiros cursos, vinculada à necessidade de formação do Estado Nacional, após a independência, marcou, desde o início, o ensino jurídico brasileiro como um ensino voltado à formação de uma ideologia de sustentação política e à formação de técnicos para ocuparem a burocracia estatal.

Isso não significa, e já foi salientado, que os mais tradicionais cursos jurídicos no Brasil não tenham cultivado grandes profissionais. Consoante Venâncio Filho (2011, p. 133), as academias foram responsáveis pela formação de ilustres figuras de destaque no cenário nacional, sobretudo na política, na literatura, no jornalismo, mas que, conforme ressalta, "o brilho desta geração se exerceu muito mais fora dos umbrais das Arcadas do que no estudo do Direito e no comparecimento às preleções dos professores da casa". Dessa maneira, não é preciso muito esforço para perceber a verdadeira contribuição dos cursos jurídicos para os contornos que se pretendia dar ao país. As Academias de direito eram responsáveis pelo desenvolvimento ideológico ${ }^{7}$ dos in-

\footnotetext{
6 De acordo com Schwarcz (1993, p. 142), essa notoriedade advinha "menos do curso em si, ou da profissão stricto sensu, e mais da carga simbólica e das possibilidades políticas que se apresentavam ao profissional do Direito. Com efeito, das fileiras dessas duas faculdades saíram grandes políticos - entre ministros, senadores, governadores e deputados -, pensadores que ditaram os destinos do país. Sinônimo de prestígio social, marca de poder político, o bacharel se transformava em uma figura especial em meio a um país interessado em criar elites próprias de pensamento e direção política".

7 Para uma melhor compreensão, é importante ressaltar que será atribuída ao vocábulo ideologia - ou quaisquer de seus desdobramentos - uma conotação que represente o conjunto de ideias e/ou convicções de um indivíduo ou determinado grupo que sirva para nortear as suas condutas sociais e políticas.
} 
telectuais que exerceriam importantes cargos na administração pública. Nesse sentido, a criação dos referidos cursos no Brasil reflete a necessidade de instalação de uma formação vinculada ao Estado e suas necessidades, com o intuito de fazer prevalecer o modelo de organização política e econômica então desejado pela a elite dominante à época (BASTOS, 1998, p. 16).

Dito de outra forma, a Graduação em Direito no país não necessariamente preparava os bacharéis para as questões práticas da vida jurídica, uma vez que tais cursos tinham o objetivo de formar profissionais hábeis a compor a burocracia de um país em desenvolvimento. É justamente acerca da construção do Estado brasileiro pela elite política dominante que trataremos na sequência, dando-se ênfase ao papel do ensino jurídico como instrumento de formação ideológica dos bacharéis.

\section{A CONSTRUÇÃO DO ESTADO BRASILEIRO PELA ELITE: O Papel do Ensino Jurídico na Formação Ideológica dos Burocratas}

Já mencionou-se que a criação dos primeiros cursos de Direito no Brasil confunde-se com a própria construção do país, não apenas pelo fato de ter sido objeto de debate já nas primeiras reuniões da Assembleia Constituinte, logo após a declaração da independência, mas, principalmente, porque as faculdades de São Paulo e Olinda/Recife teriam servido de centros de formação e treinamento da elite política responsável pelo exercício dos mais elevados cargos da burocracia estatal.

Essa opção de composição do governo brasileiro foi diretamente influenciada pela tradição portuguesa de profissionalização dos funcionários públicos, haja vista que considerável parte da elite imperial, então dominante no Brasil pós-independência, tinha sido formada em Coimbra e, dessa maneira, reproduziu no território nacional os ensinamentos e conviç̧̃̃es acerca da política de centralização do poder e treinamento de profissionais para os quadros da administração até então predominantes na metrópole.

Trata-se do estabelecimento de uma configuração em que predominava a manutenção de uma elite coesa incumbida do poder decisório acerca do projeto de construção do Estado nacional. Partia-se da premissa de que, quanto mais harmônica fosse a ideologia do grupo, mais estável seria o processo de instauração do modelo de dominação política desenhado. No Brasil, essa homogeneidade da elite era forjada por meio da educação superior - no caso, os cursos de Direito - à semelhança do que ocorria em Portugal, tendo as academias de São Paulo e Olinda/Recife representado importante instrumento de imersão político-ideológico das forças dominantes (CARVALHO, 2003, p. 35).Tais razões nos levam a corroborar o raciocínio segundo o qual o contexto político, social e econômico em que se insere o surgimento dos primeiros cursos de Direito no Brasil, indica que a sua criação foi uma escolha da então elite dirigente no intuito de possibilitar o processo de formação do país de acordo com os contornos e interesses que lhe eram peculiares à época, ou seja "educação superior a serviço do estado e das elites econômicas e políticas dele constituintes, não da nação" (MARQUES, 2013, p. 555).

Ao invés de instigar o efetivo conhecimento jurídico, as academias de São Paulo e Olinda/Recife serviam como instrumento de formação ideológica dos profissionais que, posteriormente, integrariam os quadros da estrutura administrativa e, como tal, seriam os responsáveis pelo projeto de desenvolvimento do país. Tais razões justificam o interesse do governo no arranjo do ensino jurídico, pois "a organização dos cursos de Direito acabou voltando-se muito mais para atender às necessidades do Estado Nacional que necessitava formar sua burocracia do que para atender às expectativas jurídicas da sociedade" (MARTINS, 2002, p. 64).

Nesse sentido, uma análise mais apurada da história e do surgimento dos primeiros cursos de direito no Brasil nos permite perceber que o ensino jurídico à época era peça fundamental para composição do sistema ideológico, político e burocrático do Estado que se encontrava em processo de construção (RODRIGUES, 1988, p. 16). Assim, era no âmbito das faculdades que ocorria a integração das ideias que prevaleceriam na tomada de decisão do modelo de Estado que se pretendia forjar a partir dos interesses da elite dominante (o liberalismo), por intermédio do fornecimento de bacharéis para a formação da elite política e composição dos cargos da burocracia estatal.

De acordo com Carvalho (2003, p. 65), a educação superior teria representado elemento poderoso na unificação ideológica da elite imperial por três razões:

Em primeiro lugar, porque quase toda a elite possuía estudos superiores, o que acontecia com pouca gente fora dela: a elite era uma ilha de letrados num mar de analfabetos. Em segundo lugar, porque a educação superior se concentrava na formação jurídica e fornecia, em consequência, um núcleo homogêneo de conhe- 
cimentos e habilidades. Em terceiro lugar, porque se encontrava, até a Independência, na Universidade de Coimbra e, após a Independência, em quatro capitais provinciais, ou duas, se considerarmos apenas a formação jurídica.

De fato, como o acesso aos cursos de Direito era praticamente um privilégio da elite nacional, o ensino jurídico foi capaz de permitir o controle do Estado pelo grupo dominante no país, pois eram justamente os egressos das faculdades que seriam recrutados para compor o aparato estatal. As tomadas de decisão acerca do desenvolvimento do estado brasileiro concentrava-se, pois, nas mãos de um grupo de intelectuais oriundos de restrita camada social e que coadunavam dos mesmos conhecimentos e habilidades produzidas nas Academias.

É a partir de tais constatações que se pode afirmar que as primeiras faculdades de Direito criadas no território nacional desempenhavam, pelo menos, duas funções práticas (mas nenhuma delas ligada à produção do conhecimento jurídico): a formação de uma elite intelectual própria, ideologicamente integrada de acordo com os interesses do modelo político-liberal dominante; e servir de centro de recrutamento de profissionais para a formação dos quadros da gestão estatal. Nesse sentido, afirma Falcão (1984, p. 17):

A primeira, bem mais complexa e menos evidente, situa-se ao nível cultural-ideológico. As Faculdades de Direito constituíram-se nas principais instituições responsáveis pela sistematização teórica, ou científica, como então entendiam a nova ideologia político-jurídica, o liberalismo, a quem se confiava a integração ideológica do Estado Moderno que a elite projetava. A segunda, mais perceptível, nem por isso menos importante, tratava de operacionalizar essa ideologia. Vale dizer, formar os quadros para a gestão do Estado nacional. É o prelúdio da burocracia federal.

A profissionalização da política no interior das faculdades demonstrava que o ensino jurídico representava um mecanismo político-ideológico de recrutamento dos agentes que, ao término do curso, estariam incumbidos da direção dos negócios públicos. Esse processo de formação dos intelectuais configurava fator estratégico de unificação da elite política dominante que integraria a burocracia estatal e, consequentemente, permitiria ao bacharel uma função central neste modelo liberal de exercício do poder (ADORNO, 1988, p. 78).

A esta elite nacional política, Pang e Seckinger (1972, p. 216) chamaram de mandarins, assim considerados "os membros que tipicamente vieram de origens socioeconômicas e educacionais semelhantes, manifestaram aspirações políticas semelhantes e subscreveram ideias políticas e sociais convencionais" (tradução nossa). ${ }^{8}$ No período imperial brasileiro, com o projeto liberal do país ainda em desenvolvimento, esse papel foi desempenhado pelos bacharéis que, antes treinados em Coimbra, passaram a ser formados nas academias jurídicas de São Paulo e Olinda/Recife.

Foi justamente por meio dessas duas faculdades nacionais - e antes, em Coimbra - que se formaram grandes expoentes da elite política brasileira no período imperial, profissionais que se destacaram pela atuação no exercício de diversas funções da carreira pública. A Graduação em Direito, apesar de não representar a certeza de uma formação jurídica de qualidade, era praticamente uma via de acesso aos mais elevados cargos na administração estatal, transformando os bacharéis em verdadeiros protagonistas neste cenário, conforme asseveram Barman e Barman (1976, p. 44):

A elite do Brasil Imperial foi, então, construída em torno de uma geração de homens que, formados em Coimbra na década de 1820, aumentaram seu número e seu poder assimilando os primeiros formandos da nova escola de direito do Brasil. Nos primeiros anos, existia uma suficiência de emprego público para todos os graduados em direito, que monopolizavam ao mesmo tempo a política e o judiciário. A probabilidade da associação de elite foi conferida pelo simples ato de graduação da faculdade de direito (tradução nossa). ${ }^{9}$

\footnotetext{
8 "The members of which typically came from similar socioeconomics and educational backgrounds, manifested similar political aspirations and subscribed to conventional political and social ideas".

9 "The elite of Imperial Brazil was, then, constructed around a generation of men who, graduating from Coimbra in the $1820 \mathrm{~s}$, increased their number and their power by assimilating the first graduates form the new Brazilian's law school. In the early years a sufficiency of public employment existed for all law graduates, who monopolized at the same time both the politics and the judiciary. The probability of the elite membership was conferred by the mere act of graduation from law school".
} 
Pois bem, levando em consideração que os bacharéis eram recrutados para a composição da burocracia estatal e, sendo assim, também atuavam como membros da organização judiciária, o capítulo que segue sem a pretensão de exaurir o estudo sobre o tema - trará uma breve abordagem acerca do Poder Judiciário na ordem política imperial e o reflexo da função por ele desempenhada na sociedade, partindo-se do pressuposto de que suas raízes estão intimamente ligadas ao modelo português de organização burocrática, fazendo desta um traço característico da magistratura brasileira.

\section{REFLEXOS DA BUROCRACIA NO PODER JUDICIÁRIO BRASILEIRO}

As breves considerações, até então esposadas, tiveram o escopo de ressaltar duas constatações que se entende indispensáveis para a compreensão do que será traçado nas linhas que seguem: primeiro, que a criação dos cursos de Direito não teria sido parte do projeto de universalização do sistema educacional à população brasileira, mas uma estratégia da elite nacional em manter a coesão do pensamento político-ideológico de construção do país; segundo, que as academias funcionavam como mecanismo de formação e treinamento de profissionais que serviriam à burocracia estatal, produzindo bacharéis sem muita preocupação na absorção de conhecimentos jurídicos, mas bastante atuantes na gestão do Estado.

Estabelecidas essas premissas, é importante ressaltar que a organização burocrática era um traço marcante do governo português em relação à colônia brasileira, característica esta da qual não escapava o Poder Judiciário. A preocupação com a centralização do poder nas mãos do monarca refletia no sistema de nomeação dos magistrados que, dentre outras atribuições, eram verdadeiros representantes dos interesses reais no território brasileiro. Em contrapartida, os juízes e desembargadores utilizavam-se desta carreira como mecanismo de ascensão social (SCHWARTZ, 2011, p. 227), usufruindo de todos os privilégios que o título Ihes conferia, padrão que permaneceria também no período pós-independência.

A estrutura judiciária portuguesa do século 18 - que, para efeitos do presente artigo entende-se como matriz da qual foi pensado o modelo imperial - pode ser reconhecida por meio de três características: a hierarquização, a definição de contornos burocráticos devidamente precisos e a rotatividade dos cargos públicos (WEHLING; WEHLING, 2004, p. 275), traços que, se não foram mantidos em sua integralidade, pelo menos podem ser lembrados na forma como se projetou a organização judiciária brasileira.

A hierarquia é um traço que pode ser facilmente constatado mediante a distribuição vertical das funções no arcabouço judiciário, com a composição de órgãos inferiores (juízes) e superiores (tribunais). Acrescente-se a isto o fato de ser uma estrutura composta por profissionais que possuem uma formação específica - no caso, a jurídica - e propensos a desenvolver uma atividade de competência própria, por meio de método decisional técnico - o ato de julgar -, elementos que, na visão de Rocha (1995, p. 45), evidenciam a organização burocrática do Poder Judiciário.

Obviamente que a manutenção deste corpo burocrático da magistratura era parte da estratégia de dominação política que se pretendeu estabelecer à época e, como tal, implicou determinadas condutas dos magistrados e atuação do próprio Poder Judiciário. Assim, nesses primeiros momentos de afirmação dos interesses da elite imperial e fortalecimento do Estado, tornava-se indispensável a formação de um grupo político ideologicamente unificado para o exercício das atribuições estatais, por meio do treinamento que era realizado nas já mencionadas faculdades de Direito de São Paulo e Olinda/Recife, de onde provinham os bacharéis, já preparados para a ocupação dos cargos públicos.

Não se pode olvidar, ressalte-se, que o Estado representava o maior empregador para os letrados que ele mesmo formava, motivo mais do que suficiente para ocasionar uma simbiose entre elite política e burocracia, com a ocupação simultânea de cargos em ambos os segmentos. Nesse sentido, conforme aduz Carvalho (2003, p. 99), o magistrado acumulava habilidades suficientes para o exercício do poder público, dada a sua formação educacional (treinamento) aliada à experiência de aplicação da lei. Para o autor

Partimos da suposição de que o emprego público era a ocupação que mais favorecia uma orientação estatista e que melhor treinava para as tarefas de construção do Estado na fase inicial de acumulação do poder. A suposição era particularmente válida em se tratando de magistrados que apresentavam a mais perfeita combinação de elementos intelectuais, ideológicos e práticos favoráveis ao estatismo. 
Com isso, era bastante comum a inclinação do magistrado para atividades não essencialmente jurisdicionais, na medida em que "a nomeação para um cargo judiciário era a forma privilegiada de ingresso na carreira política imperial" (KOERNER, 2010, p. 44), ou seja, não raras vezes os juízes ocupavam mais de um cargo simultaneamente (como deputados ou senadores, por exemplo). A esta possibilidade de ingresso na carreira política já estavam atentas as faculdades de Direito, que pouco ofertavam em termos de formação jurídica mas preparavam o bacharel para o exercício das funções públicas.

De outro lado, em se tratando de um país com vasto território nacional, havia determinadas localidades que o poder imperial não alcançava e, portanto, necessitava de um representante para sua afirmação. Essa função coube aos magistrados, uma vez que a ordem política e a estabilidade do poder central pressupunham a mediação das relações entre o governo e as elites locais (KOERNER, 2010, p. 53), atuando os juízes como mandatários do imperador com vistas a preencher qualquer possível lacuna espacial que desse margem à autonomia dos potentados regionais.Não se quer afirmar com isso, todavia, que esse modelo conservador de dominação política tenha restado incólume durante os anos iniciais de formação do país. Na verdade, irresignados com essa forma imperial de controle social, os liberais editaram, em 1827, a lei que criava a figura do juiz de paz, um magistrado sem treinamento e que seria eleito para exercer, em âmbito local, a função conciliativa e os poderes de julgamento dos assuntos de menor relevância.Tratava-se, assim, de profissionais que seriam escolhidos por meio de eleição nas paróquias e que assumiriam parte das atribuições antes inerentes a magistrados tradicionalmente nomeados pelo imperador, o que levou Flory $(1986$, p. 81) a constatar que "os reformadores liberais fizeram do juiz de paz o porta-estandarte de suas preocupações filosóficas e práticas: formas democráticas, localismo, autonomia e descentralização" (tradução nossa). ${ }^{10}$ Dito de outra forma, apesar do movimento regressista dos conservadores que iria ocorrer anos depois, a criação dos juízes de paz representou uma nítida tentativa de ampliação da participação popular na justiça por meio da limitação dos poderes do monarca na composição da estrutura judiciária.

Se por um lado é verossímil a constatação de contornos burocráticos na organização judicial brasileira e a predominância de interesses das elites políticas na construção de um modelo de Estado nacional, não é menos verdade que a análise da atuação do Poder Judiciário exige que não descuidemos desses fatores como componentes de uma justiça para e pela sociedade, sobretudo no que concerne à promessa de democratização do seu acesso e à forma de apreciação dos conflitos.

De fato, com o seu surgimento, o Estado - responsável pela organização da vida em sociedade - passou a exercer o monopólio da criação e da aplicação do Direito, fazendo da jurisdição o meio tradicional de apreciação de controvérsias e de acesso à justiça, função que desempenha por intermédio do Poder Judiciário, o que justificaria a expressão acesso à justiça poder ser entendida, num primeiro momento, como sinônimo de ingresso aos órgãos judiciários, posto que a estes foi conferida a função de resolução de conflitos e concretização de direitos.

É necessário se reconhecer, no entanto, que, numa concepção mais contemporânea, ao acesso à justiça deve ser dada uma conotação mais ampla, tal qual proposta na clássica obra de Cappelletti e Garth (1988, p. 15), no sentido de compreendê-la sob a perspectiva da efetividade, consubstanciada na incumbência de o Estado proporcionar a facilitação das vias de ingresso aos tribunais e, sobretudo, responder às demandas de forma adequada e tempestivamente. Esta, porém, não era uma característica inerente ao Poder Judiciário brasileiro pós-independência. Pelo contrário, ele mostrou-se acessível apenas para a afirmação de interesses políticos das elites na formação de uma sociedade escravista, servindo como instrumento de controle social repressivo das classes dominadas (KOERNER, 1999, p. 46).

Dessa forma, é inegável que não se possa desprezar o papel assumido pelo Poder Judiciário no projeto de emancipação do Estado brasileiro. A organização burocrática dos órgãos judiciais, característica herdada do modelo de colonização português, influenciou sobremaneira a composição e atuação da justiça imperial, quer seja no recrutamento de profissionais treinados para a assunção de cargos públicos - e que em razão disto faziam da magistratura uma possibilidade de ascensão na carreira política -, quer seja na reprodução dos interesses da classe dominante por meio das vias judiciais.

\footnotetext{
10 "Los reformadores liberales hicieron al juez de paz el portaestandarte de sus propias preocupaciones filosóficas y prácticas: formas democráticas, localismo, autonomía e descentralización".
} 


\section{CONSIDERAÇÕES FINAIS}

Essas breves considerações foram elaboradas no intento de demonstrar os motivos que ensejaram a instalação dos primeiros cursos jurídicos no Brasil em meados de 1827. Em verdade, utilizando o suporte fornecido pela historiografia para análise do contexto social que predominava à época, restou evidenciado que a criação das faculdades de Direito de São Paulo e Olinda/Recife foi uma opção da elite política que, mesmo ciente dos elevados índices de analfabetismo da população brasileira, preferiu dar prioridade ao Ensino Superior, mantendo o caráter excludente da educação nacional.

Essa escolha, como se viu, teria sido motivada pela proposta de formação do Estado brasileiro tal qual pretendido pela então elite, um modelo influenciado pela tradição portuguesa, com características burocráticas de monopolização do poder e dominação política por parte da classe dominante. Assim, o ensino jurídico seria o instrumento utilizado para manutenção de uma elite de bacharéis ideologicamente homogênea que, posteriormente, seria recrutada para compor os mais elevados cargos públicos, tornando-se responsável pelas tomadas de decisão no desenvolvimento do país.

Nesse sentido, ainda que se possa argumentar alguns dos fatores que teriam justificado as constantes críticas à qualidade do ensino jurídico no Brasil Império, o fato é que das academias de São Paulo e Olinda/ Recife saíram boa parte dos mais relevantes profissionais da história brasileira, apesar do destaque da atuação desses indivíduos estar, quase sempre, alheia à carreira jurídica. Isso não significa que os referidos cursos não tenham alcançado a sua finalidade; pelo contrário, o intuito não era a formação jurídica do bacharel, mas o seu treinamento para ascensão ao poder estatal, inclusive pela via do Judiciário, revelando as implicações do ensino jurídico para a formação do Estado nacional tal qual pretendido pelas elites políticas.

\section{REFERÊNCIAS}

ADORNO, Sérgio. Os aprendizes do poder: o bacharelismo liberal na política brasileira. Rio de Janeiro: Paz e Terra, 1988.

BARMAN, Roderick; BARMAN, Jean. The role of the law graduate in the political elite of Imperial Brazil. Journal of interamerican studies an world affairs, v. 18, n. 4, , Nov. 1976.

BASTOS, Aurélio Wander. O ensino jurídico no Brasil. Rio de Janeiro: Lúmen Juris, 1998.

BRASIL. Constituição Política do Império do Brasil. 1824. Disponível em: http://www.planalto.gov.br/ccivil_03/Constituicao/ Constituicao24.htm.

CAPPELLETTI, Mauro; GARTH, Bryant. Acesso à justiça. Tradução Ellen Gracie Northfleet. Porto Alegre: Fabris, 1988.

CARVALHO, José Murilo de. A construção da ordem: a elite política imperial. Rio de Janeiro: Civilização Brasileira, 2003.

FALCÃO, Joaquim. Os cursos jurídicos e a formação do Estado Nacional. In: Os advogados: ensino jurídico e mercado de trabaIho. Recife: Fundação Joaquim Nabuco, 1984.

FEITOSA, Gustavo Raposo Pereira. Ensino do direito, teoria jurídica e magistratura: em busca de um modelo. Revista Pensar, Fortaleza, v. 11, p. 108-117, fev. 2006.

FLORY, Thomas. El juez de paz y el jurado en el Brasil imperial,1808-1871: control social y estabilidad política en el nuevo Estado. Trad. Mariluz Caso. México: FCE, 1986.

HOLANDA, Sérgio Buarque de. Raízes do Brasil. São Paulo: Companhia das Letras, 1995.

KOERNER, Andrei. Habeas corpus, prática judicial e controle social no Brasil (1841-1920). São Paulo: IBCCrim, 1999.

KOERNER, Andrei. Judiciário e cidadania na Constituição da República brasileira (1841-1920). 2. ed. Curitiba: Juruá, 2010.

LUZURIAGA, Lorenzo. História da educação e da pedagogia. 18. ed. São Paulo: Nacional, 1990.

MARQUES, Waldemar. Estado, sociedade e educação superior no Brasil Império: o passado presente. Avaliação, Campinas; Sorocaba, SP, v. 18, n. 3, p. 547-566, nov. 2013.

MARTINS, Daniele Comin. A criação dos cursos jurídicos e a elaboração legislativa do império. Sequência, v. 23, n. 44, p. 55-75, 2002.

MEDINA, Paulo Roberto de Gouvêa. Do bacharelismo à bacharelice: reflexos desses fenômenos nos cursos jurídicos, ao longo do tempo. In: Ensino Jurídico: literatura e ética. Brasília: OAB, 2009.

PANG, Eul-Soo; SECKINGER, Ron L. The mandarins of Imperial Brazil. Comparative studies in Society and History, v. 14, n. 217245, Mar. 1972.

PAULO FILHO, Paulo. O bacharelismo brasileiro (da colônia à república). Campinas: Bookseller, 1997. 
REALE JÚNIOR, Miguel. Criação e degenerescência do ensino jurídico. Revista USP, São Paulo, n. 100, p. 87-96, dez./jan./fev. 2013-2014.

RIBEIRO, Maria Luisa Santos. História da educação brasileira: a organização escolar. 15. ed. rev. e ampl. Campinas: Autores Associados, 1998.

ROCHA, José de Albuquerque. Estudos sobre o Poder Judiciário. São Paulo: Malheiros, 1995.

RODRIGUES, Horácio Wanderlei. Ensino jurídico: saber e poder. São Paulo: Editora Acadêmica, 1988.

SCHWARCZ, Lilia Moritz. O espetáculo das raças: cientistas, instituições e questão social no Brasil. São Paulo: Companhia das Letras, 1993.

SCHWARTZ, Stuart B. Burocracia e sociedade no Brasil colonial: a Suprema Corte da Bahia e seus juízes - 1609-1751. São Paulo: Perspectiva, 2011.

VENÂNCIO FILHO, Alberto. Das arcadas ao bacharelismo: 150 anos de ensino jurídico no Brasil. São Paulo: Perspectiva, 2011. WEHLING, Arno; WEHLING, Maria José. Direito e justiça no Brasil colonial: o Tribunal da Relação do Rio de Janeiro (1751-1808). Rio de Janeiro: Renovar, 2004.

WOLKMER, Antônio Carlos. História do Direito no Brasil. Rio de Janeiro: Forense, 1999.

XAVIER, Maria Elizabete Sampaio Prado. Poder político e educação de elite. São Paulo: Cortez Editora; Autores Associados, 1980. 